Document downloaded from:

http://hdl.handle.net/10251/104805

This paper must be cited as:

Tello-Oquendo, FM.; Navarro-Peris, E.; Gonzálvez-Maciá, J. (2017). New characterization methodology for vapor-injection scroll compressors. International Journal of Refrigeration. 74:528-539. doi:10.1016/j.jirefrig.2016.11.019

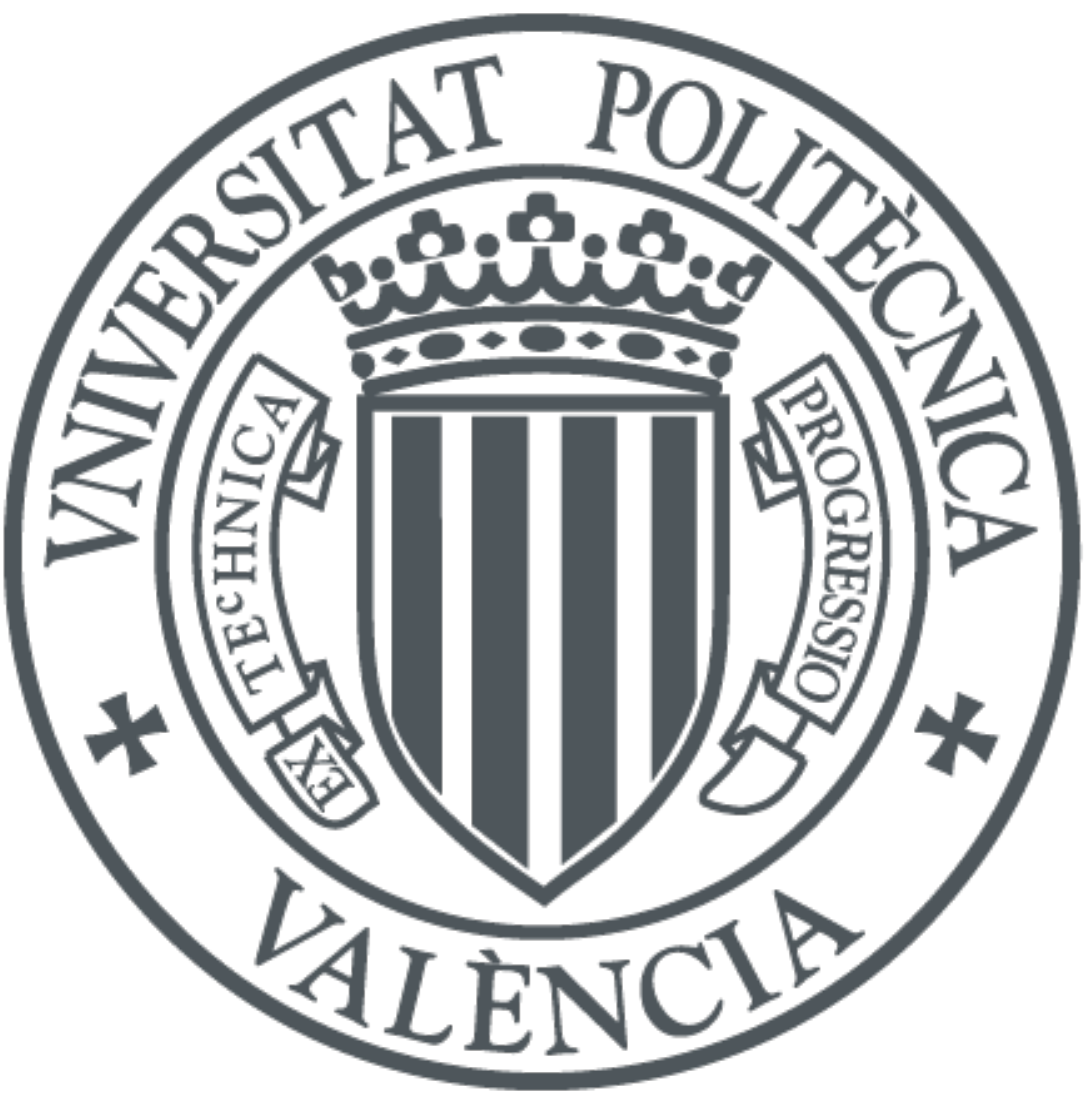

The final publication is available at

https://doi.org/10.1016/j.jirefrig.2016.11.019

Copyright Elsevier

Additional Information 


\title{
NEW CHARACTERIZATION METHODOLOGY FOR VAPOR-INJECTION SCROLL COMPRESSORS
}

\author{
Fernando M. Tello-Oquendo a,*, Emilio Navarro-Peris ${ }^{a}$, José Gonzálvez-Maciá a \\ a Universitat Politècnica de València, Instituto Universitario de Ingeniería Energética, \\ Camino de Vera, s/n, Valencia, 46022, Spain. \\ * Corresponding author. Tel.: +34 963879 120, Fax: +34 963879 126, E-mail address: \\ fertelo1@upvnet.upv.es (Fernando Tello)
}

\begin{abstract}
This paper presents a characterization methodology for vapor-injection scroll compressors (SCVI). An SCVI was characterized in a modified calorimetric test bench, which is able to control the intermediate pressure and the injection superheat independently. Based on the characterization results, the injection mass flow rate was correlated with the intermediate pressure through a linear expression, and a modified AHRI polynomial was proposed to estimate the compressor power input. The correlations were used in a simple model to predict the intermediate conditions of the SCVI installed in a heat pump prototype with an economizer. The deviations obtained for the evaporator mass flow rate, injection mass flow rate, intermediate pressure, and compressor power input were lower than $5 \%$ in all cases. The proposed methodology allows evaluating SCVI in a wide range of operating conditions, being only dependent on compressor characteristics and totally independent of the system in which it is installed.
\end{abstract}

Keywords: characterization, vapor-injection, scroll compressor, calorimetric bench 


\section{Nomenclature}

CV control valve

$\dot{\mathrm{E}} \quad$ compressor power input [W]

EEV electronic expansion valve

EV expansion valve

h enthalpy $\left[\mathrm{J} \mathrm{kg}^{-1}\right]$

$\dot{\mathrm{m}} \quad$ mass flow rate $\left[\mathrm{g} \mathrm{s}^{-1}\right]$

$\mathrm{P}$ pressure $[\mathrm{Pa}]$

$\mathrm{P}_{\mathrm{r}} \quad$ pressure ratio

Q $\quad$ capacity [W]

SCVI scroll compressor with vapor-injection

$\mathrm{SH}$ superheat

$\mathrm{T}$ temperature $\left[{ }^{\circ} \mathrm{C}\right]$

$\dot{\mathrm{V}} \quad$ swept volume $\left[\mathrm{m}^{3} \mathrm{~h}^{-1}\right]$

Greek symbols

$\rho \quad$ density $\left[\mathrm{kg} \mathrm{m}^{-3}\right]$

$\eta_{c} \quad$ compressor efficiency

$\eta_{\mathrm{v}} \quad$ volumetric efficiency

\section{Subscripts}

c condenser

dew dew point

eco economizer

e evaporator

inj injection

int intermediate

$\mathrm{s} \quad$ isentropic

tra transfer

1 compressor inlet

4 compressor discharge

5 condenser outlet

8 injection port inlet

9 evaporator inlet 


\section{INTRODUCTION}

In Europe, manufacturers characterize single-stage compressors based on the Standard (UNE-EN 13771-1, 2003). The standard proposes several procedures for testing compressors, which require the definition of three external conditions: evaporating pressure, condensing pressure and superheat at the compressor inlet. In these conditions, the mass flow rate and the power consumption have to be measured.

Based on that, compressor manufacturers provided AHRI polynomials for single-stage compressors in order to estimate the mass flow rate and the power input of the compressors when they operate in different conditions of the catalog data (AHRI Standard 540, 2015).

$$
X=C_{1}+C_{2} S+C_{3} D+C_{4} S^{2}+C_{5} S D+C_{6} D^{2}+C_{7} S^{3}+C_{8} S^{2} D+C_{9} S^{2}+C_{10} D^{3}
$$

Equation (1) represents the AHRI polynomial, where $C_{1}$ to $C_{10}$ are the regression coefficients provide by the manufacturer. $\mathrm{X}$ represents the individual published ratings (power input, refrigerant mass flow rate, cooling capacity and the like). S represents the suction dew point temperature; D represents the discharge dew point temperature. The AHRI polynomial is used to determinate the compressor performance independently of the system design for any working point within the working envelope compressor.

The characterization of vapor-injection compressors is more complex because there are two additional degrees of freedom, the intermediate pressure, and the injection temperature. For a given test matrix, when including the two additional parameters in the system, the number of experimental points increase considerably because the intermediate pressure can take several values for each operating point $\left(\mathrm{T}_{\mathrm{e}}, \mathrm{T}_{\mathrm{c}}, \mathrm{SH}\right)$. Moreover, a full characterization of these compressors requires the measurement of the injection mass flow rate.

To our best knowledge, there are no published standards for characterization of vapor-injection compressors. However, some researches have been published about vapor-injection compressors, most of them mainly focused on the experimental study of the heat pump system with economizer (Fig.1 (a)) using vapor-injection scroll compressors (Ma et al., 2003; Ding et al., 2004; Ma and Chai, 2004; Bertsch and Groll, 2008; Feng et al., 2009; Wang et al., 2009a; Xu and Ma, 2011; Roh and Kim, 2011,2012). Other authors had used in their experimental studies a vapor-injection cycle with flash tank (Fig. 1 (b)), (Xu et al., 2011, 2013; Qiao et al., 2015a, 2015b; Wang et al., 2009b; Ma and Zhao, 2008), or liquid injection (Dutta et al., 2001; Winandy and Lebrun, 2002; Cho et al., 2003).

Nevertheless, a correct characterization of the vapor-injection compressor should provide the necessary information to evaluate the compressor performance in any working point, with any intermediate conditions (intermediate pressure and inlet injection temperature). However, 
nowadays the user is not able to know the behavior of the compressor regardless of the system design. Manufacturers characterize the vapor-injection compressors in such a way that their behavior is restricted to how the system is designed internally, for example considering a temperature approach of $5 \mathrm{~K}$ in the economizer. Consequently, the intermediate conditions depend on the way in which the injection is performed (economizer, flash tank, liquid injection, etc.) and the control algorithm. Therefore, this characterization is not general and is not intrinsic of the compressor, as it is for single-stage compressors.

a)

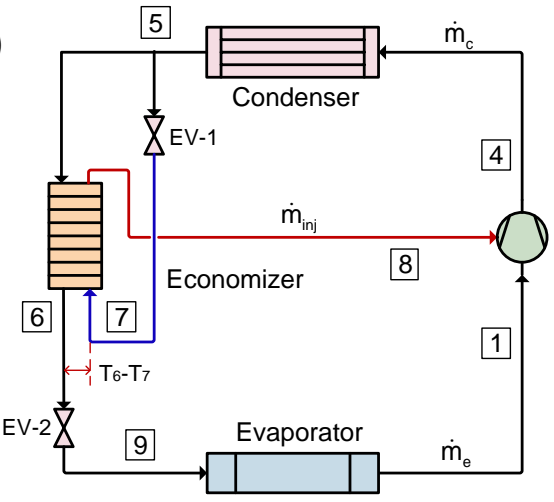

b)

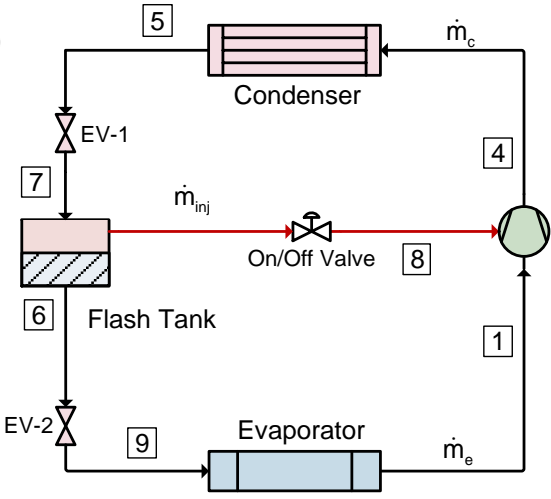

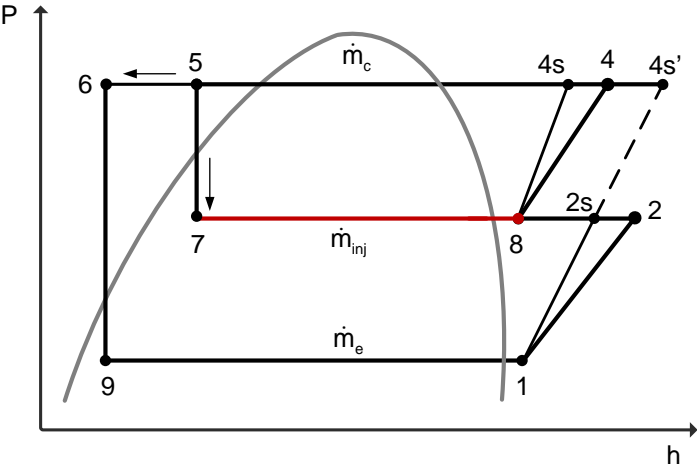

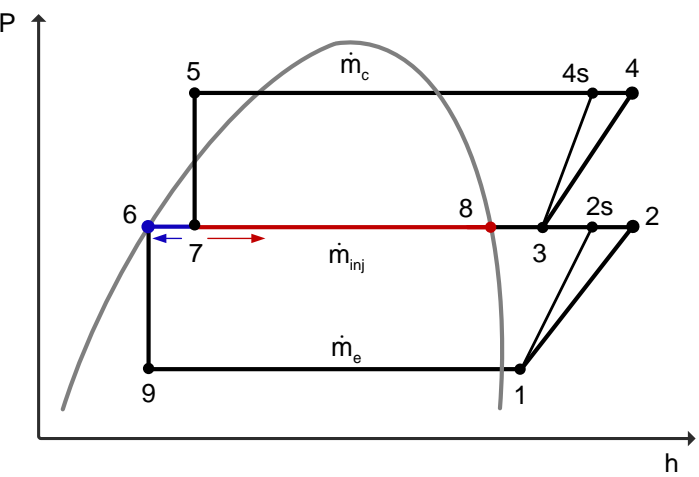

Fig. 1-a) Vapor-injection cycle with an economizer. b) Vapor-injection cycle with a flash tank.

Fig. 1 shows two typical vapor-injection cycles. The system of Fig. 1a uses a heat exchanger (economizer) to vaporize the injection mass flow rate. The intermediate conditions are set from the economizer size (UA) and the chosen mechanism of control, which is usually a thermostatic expansion valve. In this configuration, for each compressor size, a determined heat exchanger size has to be selected to define the different operating points of the compressor, which means having a set of heat exchangers (economizers) to characterize the compressor, hence the costs of the test bench increases dramatically.

In vapor-injection cycles with an economizer, for a given compressor size, the intermediate pressure is defined by the heat transfer in the economizer once the injection superheat is supplied. 
Therefore, for a given pressure ratio and an economizer size (UA), the intermediate pressure and the injection mass flow rate are fixed.

Some studies define the economizer size by setting the temperature approach in the economizer ( $\mathrm{T}_{6}-\mathrm{T}_{7}$ in Fig. 1a). For all operating points, this temperature approach is assumed constant (5 K) (Moesch et al., 2016). Basing on this consideration, manufacturers provide correlations for estimating the intermediate pressure in which the compressor have to work as equation (2). This equation shows a correlation between the dew point temperature at the intermediate pressure and the dew points temperature at the evaporating and condensing pressures (Emerson Climate Technologies, 2015).

$$
\mathrm{T}_{\text {dew,inj }}=0.8 \mathrm{~T}_{\text {dew,e }}+0.5 \mathrm{~T}_{\text {dew,c }}-\frac{19}{3} \mathrm{~K}
$$

Nevertheless, this consideration does not correspond to any real physical system because the temperature approach varies constantly in a real application with different evaporating and condensing temperatures. In addition, for the compressor testing, many heat exchangers are needed in order to maintain the temperature approach in the economizer (5 K) when the compressor works at different operating points.

A more real consideration could be to fix the economizer size for testing the compressor, like a real system arrangement. Navarro et al. (2013) presented a test campaign of a vapor-injection scroll compressor considering a wide range of nominal operating conditions. The system used was an air to water refrigerant injection circuit installed in a climatic chamber. The refrigerant vapor- injection was made through an economizer. The intermediate conditions were fixed by the control of the injection expansion valve and by the economizer size (UA). The study included the analysis of the influence of the intermediate conditions in the compressor performance and the evaluation of the separate influence of the injection superheat and the intermediate pressure. In addition, Navarro et al. (2013) introduced a simple correlation between the intermediate conditions and the inlet and outlet compressor conditions (equation (3)).

$$
\dot{\mathrm{m}}_{\mathrm{inj}}=\mathrm{K}_{0}+\mathrm{K}_{1} \dot{\mathrm{m}}_{\mathrm{e}}+\mathrm{K}_{2}\left(\frac{\mathrm{P}_{\mathrm{int}}}{\mathrm{P}_{\mathrm{e}}}\right) \dot{\mathrm{m}}_{\mathrm{e}}
$$

Equation (3) neglects the influence of the condenser pressure and the injection superheat in the injection mass flow rate estimation as they conclude that the influence of the intermediate superheat is not significant in terms of COP and that the injected refrigerant is almost independent of the condensing pressure. However, this kind of characterization is not only compressor dependent because this study was performed with a defined economizer size; it means that the 
results of the characterization also depend on the characteristics of the heat exchanger used on the test bench.

In conclusion, none of these procedures involves an intrinsic characterization of the compressor because they considered external parameters such as the economizer size, temperature approaches or other injection mechanisms. For this reason, it is necessary to find a general methodology for characterizing vapor-injection scroll compressors, which allows evaluating the compressor performance independently of the system design and of the injection method, with a not huge amount of performed tests. In this way, the information supplied allows the estimation of the compressor performance in any system.

The current paper presents a methodology for characterization of vapor-injection scroll compressors (SCVI), which depends only on the compressor characteristics. For that, an SCVI was characterized in a wide range of nominal operation conditions using a calorimetric test bench. Based on the characterization results, a correlation for the intermediate conditions was identified for this kind of compressor technology. In addition, the influence of the intermediate pressure on the evaporator mass flow rate and the compressor power input was analyzed.

Finally, the proposed characterization methodology was validated, for which, an SCVI was tested in a heat pump prototype with an economizer, and the experimental results were compared with the predicted data obtained from the proposed characterization methodology.

\section{EXPERIMENTAL SETUP}

The experimental setup consists of a typical calorimetric test bench, which was modified to add the injection line. Fig. 2 shows the scheme of the test bench used for the vapor-injection compressor characterization.

The calorimetric bench was designed to control the operating conditions of the vapor-injection compressor at the suction, discharge and injection ports (see points (1), (4) and (8) in Fig. 2). The compressor used for the characterization was an SCVI, model ZH18KVE-TFD of $17.1 \mathrm{~m}^{3} \mathrm{~h}^{-1}$ (swept volume). The SCVI was tested with R407C as a refrigerant.

The compressor testing procedure was performed based on the European Standard UNE-EN 13771-1. According to this standard, the refrigerant mass flow rate is the determining parameter to be measured, and primary and confirming measurements have to be made. The primary test procedure chosen is the secondary refrigerant calorimeter method.

A Coriolis-type mass flow meter was used as the confirming test method. In all cases, confirming tests were carried out simultaneously with the primary mass flow rate determination. The condenser mass flow rate is directly measured using a Coriolis-type (Fisher-Rosemount MicroMotion CMF025M), C-1 in Fig. 2. Several PID control loops were incorporated to allow a precise adjustment of the refrigerant conditions at compressor inlet (evaporating temperature and superheat) and outlet (condensing temperature) with a precision of $1 \mathrm{kPa}$. The calorimetric bench 
is fully automated, and designed to reach any allowable test conditions without manual adjustments. The instrument accuracies of pressure transmitter (Fisher-Rosemount 3051) and temperature transmitter (RTD-PT 100) are $0.02 \%$ and $0.05^{\circ} \mathrm{C}$, respectively.

The injection line is separated of the evaporator line in order to control independently the intermediate pressure and the injection temperature. Part of the liquid (injection mass flow rate) is derived from the condenser outlet and is expanded to the intermediate pressure in an electronic expansion valve (EEV-1 in Fig. 2). After the expansion valve, the injection mass flow rate is vaporized in a heat exchanger using a secondary circuit of a water-glycol mixture. Electric resistors control the temperature of the water-glycol mixture in order to fix the injection superheat as intermediate pressure is controlled by expansion valve EEV-1. The injection line is also equipped with a Coriolis-type mass flow meter with uncertainty of $\pm 0.025 \mathrm{~g} / \mathrm{s}$ (C-2 in Fig. 2), a pressure transducer with a precision of $0.2 \%$, an RTD with a precision of $0.1 \mathrm{~K}$, an electrovalve located before the expansion valve (EEV-1), and an electrical power meter with a precision of 0.1 $\%$.

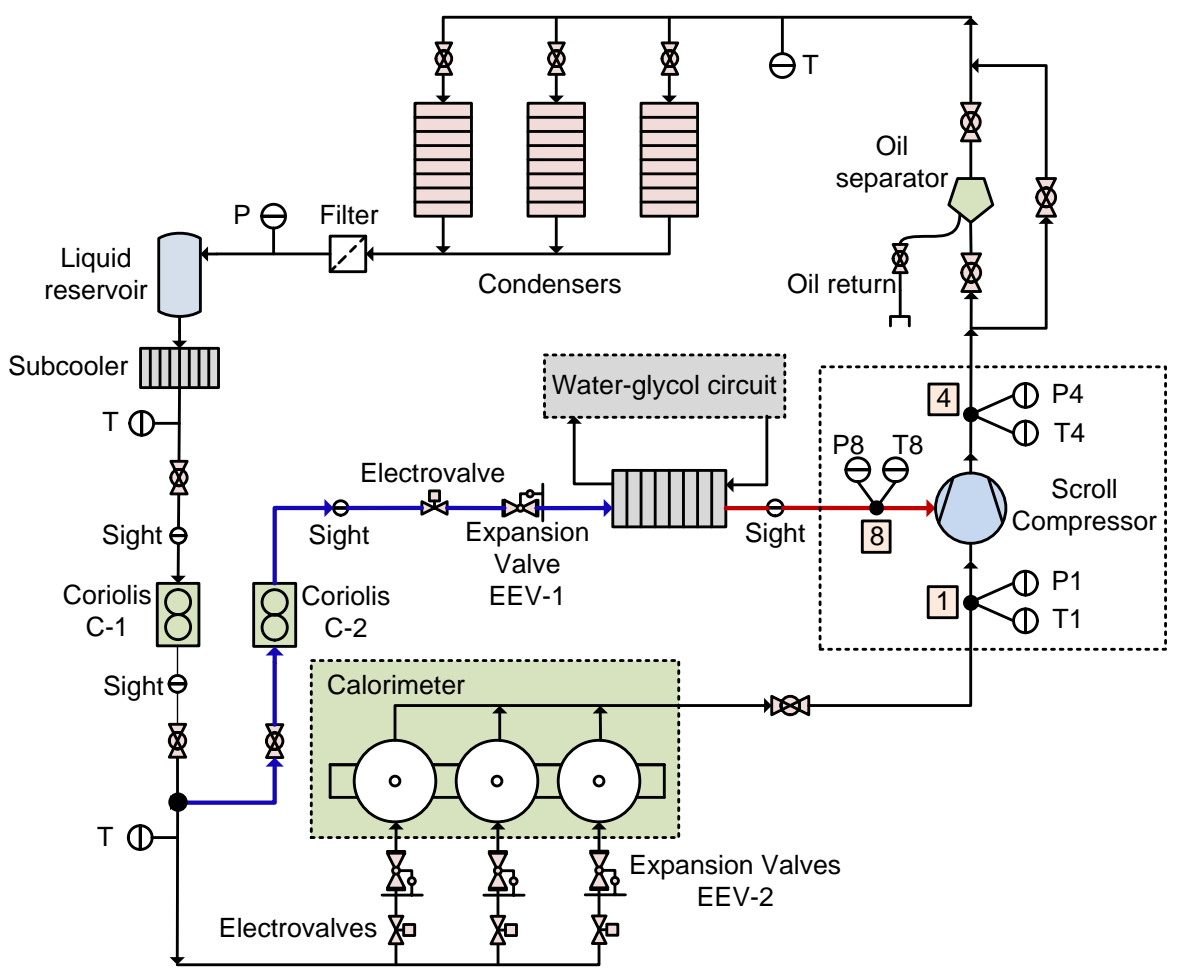

Fig. 2- Scheme of the calorimetric test bench.

The evaporator mass flow rate is calculated with equation (4) and is compared with the secondary refrigerant calorimeter based result. Based on the standard UNE-EN 13771-1, tests are valid if discrepancies between the primary and secondary method of measuring mass flow rate are less than $4 \%$, however, we obtained discrepancies lower than $2 \%$ in the calorimetric test bench for all tested points. 


$$
\dot{\mathrm{m}}_{\mathrm{e}}=\dot{\mathrm{m}}_{\mathrm{c}}-\dot{\mathrm{m}}_{\mathrm{inj}}
$$

\section{COMPRESSOR CHARACTERIZATION PROCEDURE}

Table 1 (labels "a") shows the test matrix used to characterize the vapor-injection scroll compressor. The working points were selected as a function of the compressor working envelope of the manufacturer, see Fig. 3.

Table 1 - Test matrix.

\begin{tabular}{|c|c|c|c|c|c|c|c|c|c|}
\hline \multirow{2}{*}{$\operatorname{Tc}\left({ }^{\circ} \mathrm{C}\right)$} & \multicolumn{9}{|c|}{$\operatorname{Te}\left({ }^{\circ} \mathrm{C}\right)$} \\
\hline & -25 & -20 & -17 & -10 & -8 & -3 & $\mathbf{0}$ & 2 & 10 \\
\hline 40 & $\mathrm{a}$ & $\mathrm{a}$ & & $\mathrm{a}$ & C & & $\mathrm{a}$ & & \\
\hline 50 & $\mathrm{a}$ & $a, b$ & C & $a, b$ & C & C & $a, b$ & C & $\mathrm{a}$ \\
\hline 60 & & $a, b, c$ & & $a, b$ & C & & $\mathrm{a}$ & & a, c \\
\hline 67 & & & & $\mathrm{a}$ & & & $\mathrm{a}$ & & $\mathrm{a}$ \\
\hline $\begin{array}{l}\mathrm{a}=\text { Test poi } \\
\mathrm{b}=\text { Analysi } \\
\mathrm{c}=\text { Test }\end{array}$ & $\begin{array}{l}\text { the } \\
\text { e inf } \\
\text { the } y\end{array}$ & $\begin{array}{l}\text { essor cl } \\
\text { e of the } \\
\text { ion of th }\end{array}$ & teriz & $\begin{array}{l}\text { in th } \\
\text { oress } \\
\text { tion }\end{array}$ & lor & & & & \\
\hline
\end{tabular}

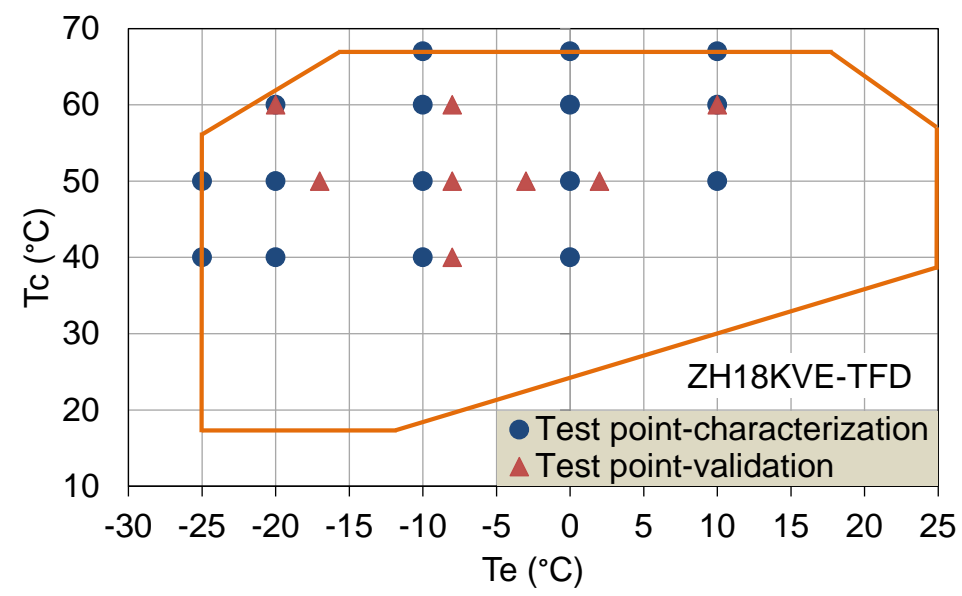

Fig. 3- Compressor working envelope and test points of the SCVI.

The procedure of characterization begins with the setting of the condensing pressure, evaporating pressure and the superheat at the compressor inlet acting on the flow rate of the water condenser, valves EEV-2, and resistors of the calorimeter, respectively. The electronic expansion valve (EEV-1 in Fig. 2) regulates the intermediate pressure. The injection superheat is fixed with the water-glycol temperature through a heat exchanger. An injection superheat of $5 \mathrm{~K}$ was chosen for testing, since in the majority of systems, the intermediate pressure control is performed with a thermostatic expansion valve. This valve needs a minimum superheat to regulate properly and to ensure that no liquid is injected; therefore, an intermediate superheat of $5 \mathrm{~K}$ is appropriate for this kind of systems. Furthermore, the injection superheat should be as low as possible to reduce the discharge temperature of the compressor. 
For all evaporating and condensing temperatures, the values of the considered parameters in the characterization are the superheat at the compressor inlet of $5 \mathrm{~K}$ and the injection superheat of 5 $\mathrm{K}$.

Once the system is in equilibrium, the total mass flow rate $\left(\dot{\mathrm{m}}_{\mathrm{c}}\right)$, the injection mass flow rate $\left(\dot{\mathrm{m}}_{\mathrm{inj}}\right)$ and the compressor power input are measured. In addition, the injection temperature $\left(\mathrm{T}_{8}\right)$, and the condenser outlet temperature $\left(T_{5}\right)$ are registered.

The volumetric efficiency is defined by the equation (5), where the number 1 is located at the compressor inlet.

$$
\eta_{\mathrm{v}}=\frac{\dot{\mathrm{m}}_{\mathrm{e}}}{\rho_{1} \dot{\mathrm{V}}_{1}}
$$

The overall compressor efficiency is defined by equation (6). This expression represents a ratio between the ideal isentropic power consumption and the real indicated work for the compressor. According to Wang et al., 2009c and Navarro et al., 2013, and based on experimental results, equation (6) suitably describes the efficiency parameter.

$$
\eta_{\mathrm{c}}=\frac{\dot{\mathrm{m}}_{\mathrm{e}}\left(\mathrm{h}_{4 \mathrm{~s}^{\prime}}-\mathrm{h}_{1}\right)+\dot{\mathrm{m}}_{\mathrm{inj}}\left(\mathrm{h}_{4 \mathrm{~s}}-\mathrm{h}_{8}\right)}{\dot{\mathrm{E}}}
$$

where $\mathrm{h}_{4 \mathrm{~s}}{ }^{\prime}$ represents the enthalpy at the compressor discharge pressure considering an isentropic compression from the compressor inlet condition (see point 1 in Fig.1a), $\mathrm{h}_{4 \mathrm{~s}}$ represents the enthalpy at the compressor discharge pressure considering an isentropic compression from the intermediate injection condition (see point 8 in Fig.1a) and E represents the compressor power input. The evaporating and condensing temperatures are dew point temperatures. The thermophysical properties of the refrigerant at the different points are calculated with the NIST REFPROP database (Lemmon et al., 2010). Results are shown in Table 2.

\section{RESULTS AND DISCUSSION}

Table 2 shows the results of the compressor characterization for each working condition of the test matrix (Table 1 - labels “a”). 
Table 2 - Results of the SCVI characterization at several working conditions.

\begin{tabular}{|c|c|c|c|c|c|c|c|c|c|}
\hline $\begin{array}{c}\mathbf{T}_{\mathbf{e}} \\
\left({ }^{\circ} \mathrm{C}\right)\end{array}$ & $\begin{array}{c}\mathbf{T}_{\mathbf{c}} \\
\left({ }^{\circ} \mathrm{C}\right)\end{array}$ & $\begin{array}{c}\dot{\mathbf{E}} \\
\left(\mathrm{kW}^{\prime}\right)\end{array}$ & $\begin{array}{c}\dot{\mathbf{m}}_{\mathbf{e}} \\
\left(\mathrm{g} \mathrm{s}^{-1}\right)\end{array}$ & $\begin{array}{c}\dot{\mathbf{m}}_{\text {inj }} \\
\left(\mathrm{g} \mathrm{s}^{-1}\right)\end{array}$ & $\begin{array}{c}\mathbf{P}_{\text {int }} \\
(\mathrm{kPa})\end{array}$ & $\begin{array}{c}\mathbf{P}_{\mathbf{e}} \\
(\mathrm{kPa})\end{array}$ & $\begin{array}{c}\mathbf{P}_{\mathbf{c}} \\
(\mathrm{kPa})\end{array}$ & $\boldsymbol{\eta}_{\mathbf{c}}$ & $\boldsymbol{\eta}_{\mathbf{v}}$ \\
\hline-25 & 40 & 3.817 & 30.16 & 10.82 & 390.15 & 172.84 & 1540.66 & 0.539 & 0.849 \\
\hline-20 & 40 & 3.978 & 37.99 & 12.02 & 456.86 & 215.03 & 1540.28 & 0.570 & 0.869 \\
\hline-10 & 40 & 4.280 & 57.20 & 13.80 & 607.42 & 319.87 & 1544.96 & 0.606 & 0.895 \\
\hline 0 & 40 & 4.411 & 83.85 & 13.99 & 783.14 & 460.71 & 1541.32 & 0.624 & 0.919 \\
\hline-25 & 50 & 4.600 & 29.31 & 13.86 & 455.38 & 173.34 & 1987.80 & 0.512 & 0.823 \\
\hline-20 & 50 & 4.805 & 36.79 & 15.48 & 525.27 & 215.08 & 1987.15 & 0.543 & 0.841 \\
\hline-10 & 50 & 5.234 & 55.81 & 18.79 & 697.36 & 320.35 & 1988.08 & 0.587 & 0.872 \\
\hline 0 & 50 & 5.502 & 81.85 & 20.33 & 885.11 & 461.50 & 1990.36 & 0.619 & 0.899 \\
\hline 10 & 50 & 5.582 & 116.30 & 20.45 & 1108.52 & 644.88 & 1987.77 & 0.635 & 0.920 \\
\hline-20 & 60 & 5.846 & 35.68 & 19.64 & 615.67 & 215.19 & 2527.89 & 0.505 & 0.815 \\
\hline-10 & 60 & 6.441 & 53.69 & 24.28 & 812.67 & 320.02 & 2528.32 & 0.544 & 0.840 \\
\hline 0 & 60 & 6.827 & 79.38 & 27.95 & 1027.30 & 461.25 & 2528.52 & 0.587 & 0.871 \\
\hline 10 & 60 & 7.001 & 113.10 & 29.72 & 1260.13 & 644.88 & 2528.70 & 0.619 & 0.893 \\
\hline-10 & 67 & 7.480 & 51.68 & 28.69 & 911.51 & 320.15 & 2972.13 & 0.504 & 0.808 \\
\hline 0 & 67 & 8.030 & 76.04 & 33.70 & 1149.98 & 461.83 & 2972.30 & 0.541 & 0.835 \\
\hline 10 & 67 & 8.318 & 108.72 & 37.98 & 1409.89 & 645.18 & 2971.81 & 0.577 & 0.859 \\
\hline
\end{tabular}

Fig. 4 depicts the compressor and volumetric efficiencies of the SCVI as a function of the pressure ratio $\left(\mathrm{P}_{\mathrm{c}} / \mathrm{P}_{\mathrm{e}}\right)$ for several condensing temperatures. At lower condensing temperatures, the compressor efficiency, and volumetric efficiency are higher. The SCVI presents high volumetric efficiency values (above 0.8) for any operating point, because the compressor does not have undesirable dead space and no inlet and outlet valves, the contact between the flanks of scrolls and their bases and upper edges is almost perfect and constant; thus, it has very good axial and radial compliance. The compressor efficiency varies from 0.5 to 0.635 . At lower condensing temperatures $\left(40^{\circ} \mathrm{C}\right)$, the compressor efficiency is greater and for higher condensing temperatures and pressure ratios (around 12), the compressor efficiency decreases to 0.5. 


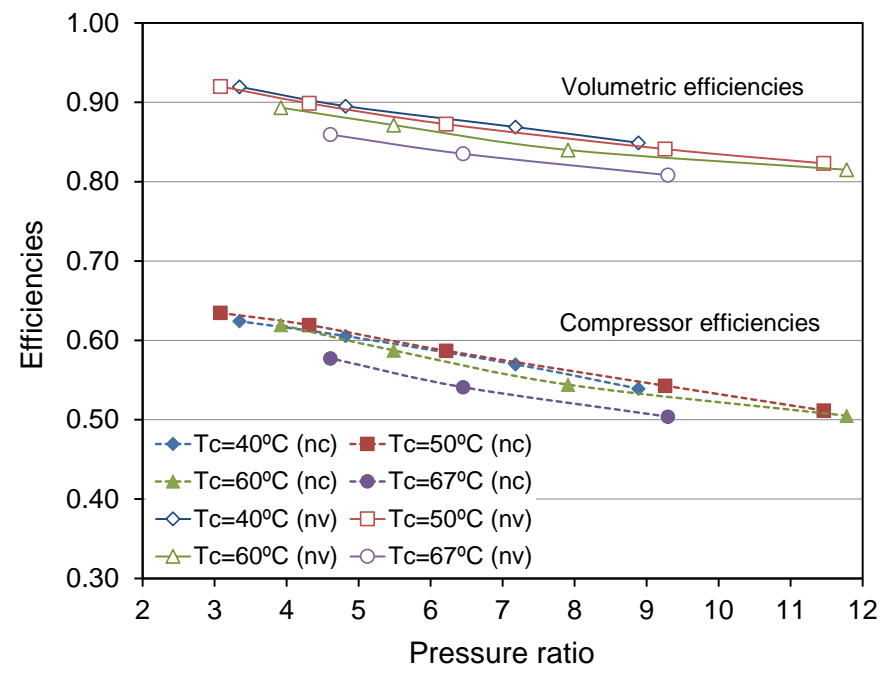

Fig. 4 - Compressor efficiency and volumetric efficiency as a function of pressure ratio at several condensing temperatures.

a)

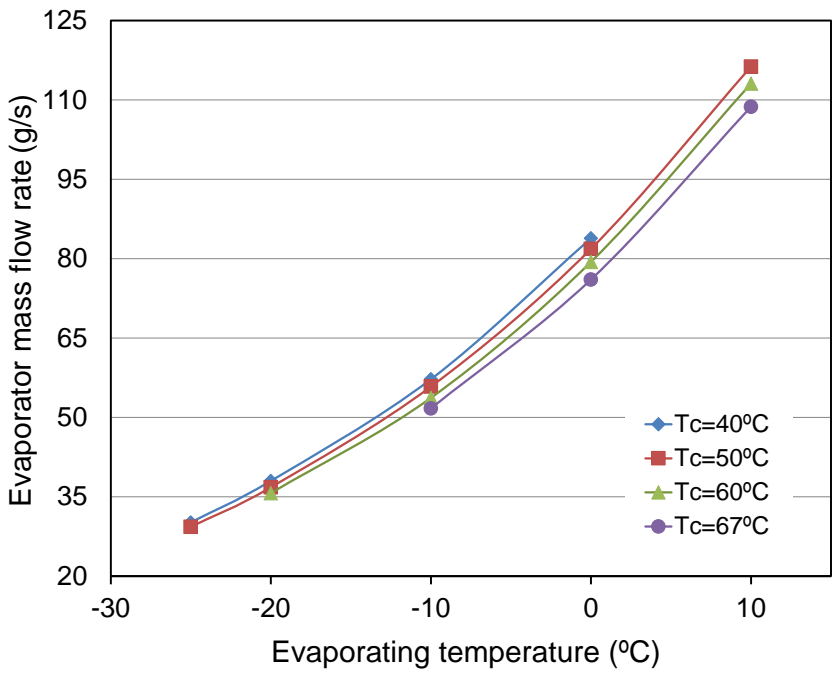

b)

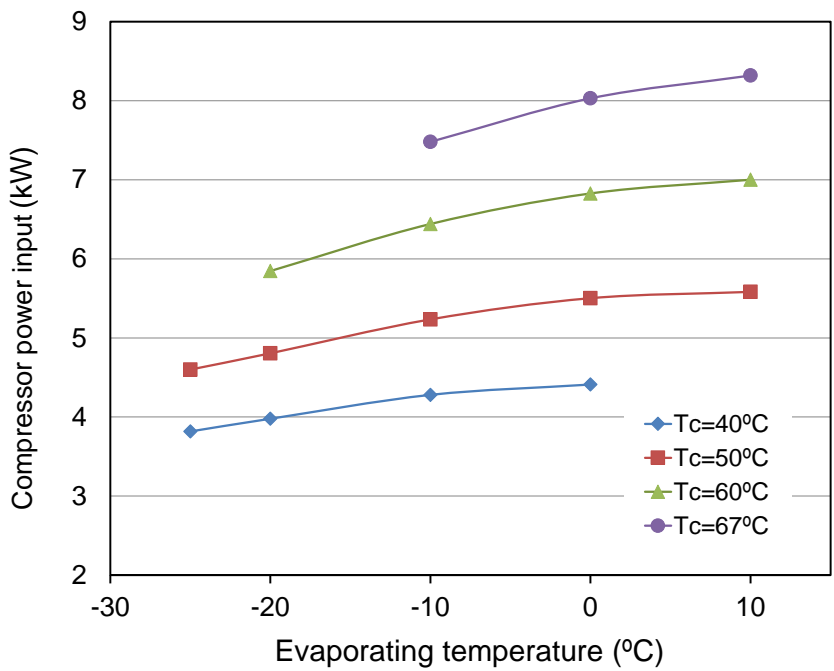

Fig. 5 - a) Evaporator mass flow rate as a function of evaporating temperature. b) Compressor power input as a function of evaporating temperature at several condensing temperatures.

Fig. 5a illustrates the evaporator mass flow rate as a function of evaporating temperature for several condensing temperatures. For a given evaporating temperature, the evaporator mass flow rate decreases slightly as the condensing temperature increases, since the pressure ratio is greater and the volumetric efficiency is reduced slightly as seen in Fig. 4. For a given condensing temperature, the evaporator mass flow rate reduces when the compressor works with lower evaporating temperatures mainly because of the reduction of the refrigerant density at the compressor inlet, and of the reduction of the volumetric efficiency at higher pressure ratios.

Fig. 5b depicts the compressor power input as a function of evaporating temperature for several condensing temperatures. At low condensing temperatures, the compressor power input is lower 
since the heat reservoirs are closer, and the compressor efficiency is slightly higher as seen in Fig. 4. For a given condensing temperature, the compressor power input increases when the evaporating temperature increases because the refrigerant mass flow rate is greater.

\subsection{Analysis of the influence of the intermediate pressure}

In this section, the influence of the intermediate pressure in the evaporator mass flow rate and the compressor power input is analyzed. In order to do that, the SCVI was tested with several intermediate pressures, maintaining constants the evaporating and condensing pressures, the inlet compressor superheat (5 K), and the injection superheat (5 K). As it was commented previously, the intermediate pressure and the injection superheat were independently controlled by the electronic expansion valve (EEV-1 in Fig. 2) and the water-glycol circuit respectively. The intermediate pressure tests were performed for different working conditions shown in Table 1labels "b”.

a)

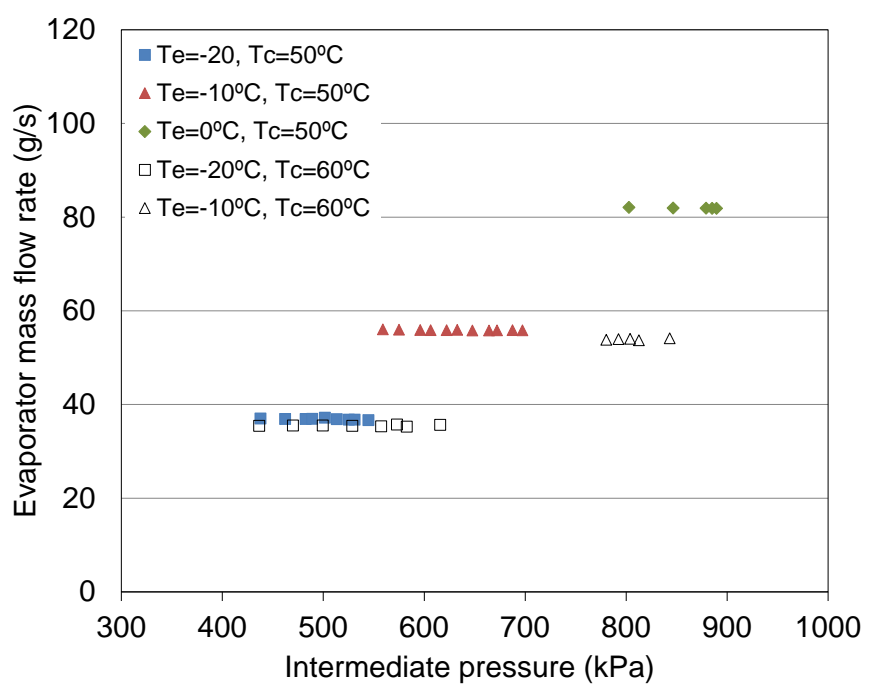

b)

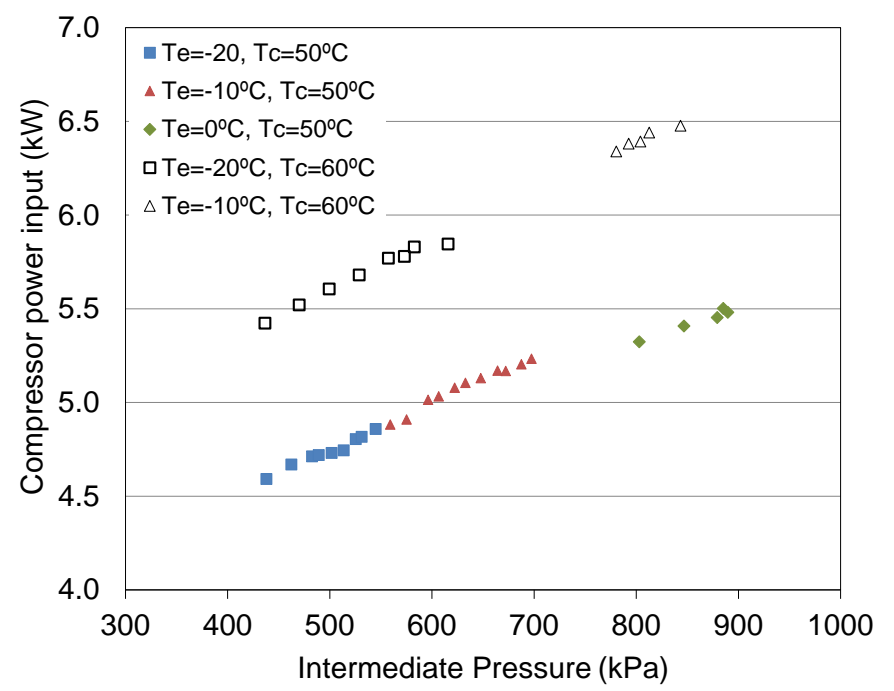

Fig. 6 - a) Evaporator mass flow rate as a function of intermediate pressure. b) Compressor power input as a function of intermediate pressure for several working points.

Fig. 6a depicts the evaporator mass flow rate as a function of the intermediate pressure for several operating points. In all tested points, the evaporator mass flow does not show a significant variation with the intermediate pressure. The evaporator mass flow rate shows a smooth decrease as the condensing temperature decreases for points with the same evaporating temperature.

Fig. 6b represents the compressor power input as a function of the intermediate pressure for several operating points. For each operating point, the compressor power input varies linearly with the intermediate pressure. Moreover, it can be observed that the trend of the curves is almost linear for all points at the same condensing temperature. 
Basing on the characterization results (Table 2) and considering the analysis of the influence of the intermediate pressure, it is proposed expressions to characterize the evaporator mass flow rate and the compressor power inlet.

The AHRI polynomial of equation (1) is used to characterize the evaporator mass flow rate of the compressor. This expression is the same as that used for single-stage compressors since the intermediate pressure does not affect the evaporator mass flow rate, as seen in Fig. 6a. The coefficients $\mathrm{C}_{1}$ to $\mathrm{C}_{10}$ were calculated by polynomial regression with the measured compressor data, the obtained correlation factor was higher than 0.99 .

The compressor power input is characterized using the equation (7). This expression is based on AHRI polynomials, but in this case, the equation (1) has to be modified in order to consider the effect of the intermediate injection. We propose the addition of a new term, which includes the product between a regression coefficient $\left(\mathrm{C}_{11}\right)$ and the dew point temperature at the intermediate pressure (I). The obtained correlation factor was also higher than 0.99 .

$\dot{\mathrm{E}}=\mathrm{C}_{1}+\mathrm{C}_{2} \mathrm{~S}+\mathrm{C}_{3} \mathrm{D}+\mathrm{C}_{4} \mathrm{~S}^{2}+\mathrm{C}_{5} \mathrm{~S} \mathrm{D}+\mathrm{C}_{6} \mathrm{D}^{2}+\mathrm{C}_{7} \mathrm{~S}^{3}+\mathrm{C}_{8} \mathrm{~S}^{2} \mathrm{D}+\mathrm{C}_{9} \mathrm{~S} \mathrm{D}^{2}+\mathrm{C}_{10} \mathrm{D}^{3}+\mathrm{C}_{11} \mathrm{I}$

\subsection{Determination of the intermediate conditions correlation for vapor-injection scroll compressors}

The relation of the injection mass flow rate and the intermediate pressure is an intrinsic characteristic of each scroll compressor because it depends on the design and construction of the compressor and the injection port location (Wang et al., 2007, 2008, 2009a).

In order to characterize vapor-injection scroll compressors independently of the injection mechanism, a relation between the injection mass flow and the rest of the working conditions must be identified.

Fig. 7 represents the injection mass flow rate as a function of the intermediate pressure, where both variables are normalized to the evaporator conditions ( $\dot{\mathrm{m}}_{\mathrm{e}}$ and $\mathrm{P}_{\mathrm{e}}$ ). Based on 16 tested points of the compressor working envelope, this figure shows that there is a linear dependence between both variables. Therefore, the obtained correlation is given in expression (8), where the coefficients A and B were obtained by linear regression with a correlation factor higher than 0.99.

$$
\begin{gathered}
\frac{\dot{\mathrm{m}}_{\text {inj }}}{\dot{\mathrm{m}}_{\mathrm{e}}}=\mathrm{A}+\mathrm{B} \frac{\mathrm{P}_{\text {int }}}{\mathrm{P}_{\mathrm{e}}} \\
\mathrm{A}=-0.383 \quad \mathrm{~B}=0.329
\end{gathered}
$$




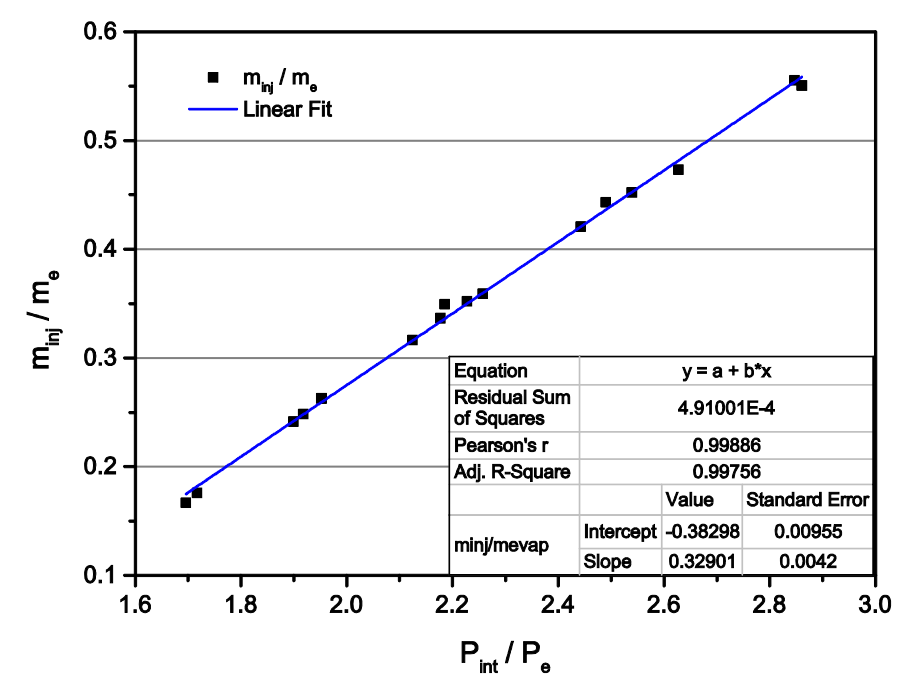

Fig. 7 - Relative injection mass flow rate as a function of the relative intermediate pressure.

Once the correlation (8) is identified, the injection mass flow rate of a determined system with a concrete injection strategy can be calculated directly for each working condition. The equation (8) is an additional AHRI polynomial required to characterize vapor-injection scroll compressors. The correlation supplies a tool to the compressor manufacturers in order to provide compressor data independently of the heat pump or refrigeration system in which the compressor will be installed.

It must be emphasized that it was not necessary to test the SCVI in more points than the required ones for the single-stage compressor characterization in order to obtain the correlation of the intermediate compressor conditions. The SCVI was tested in only a single intermediate pressure for each working condition. From these measurements, the coefficients A and B of equation (8) were adjusted.

Nevertheless, in order to verify the validity of the correlation, we also have measured the SCVI working with several different intermediate pressures for each operating point. As shown in Fig. 8, the correlation obtained above fits all measured points with a correct agreement. 


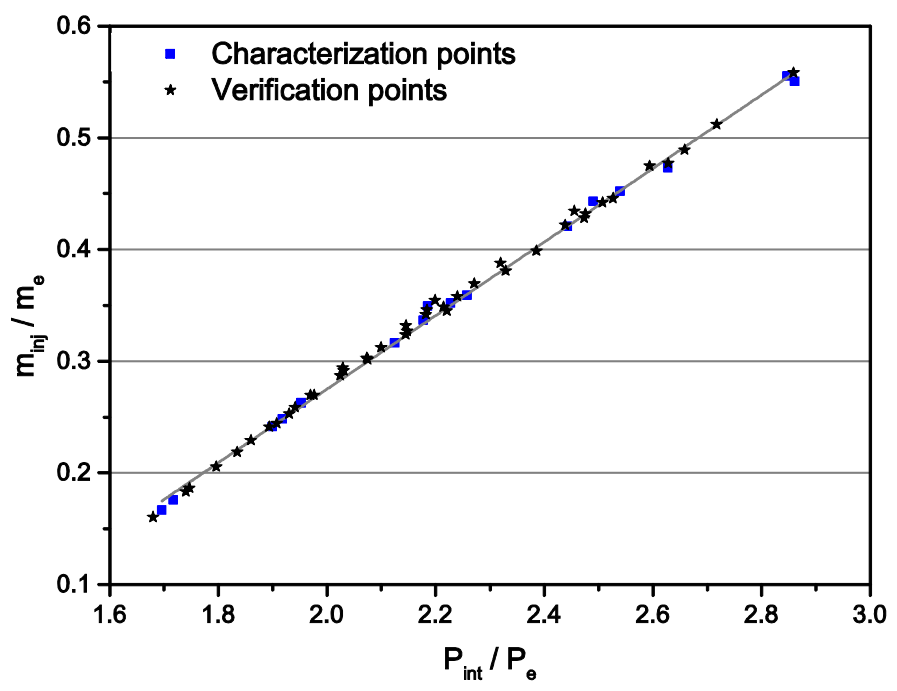

Fig. 8 - Verification of the intermediate conditions correlation.

\subsection{General model of a vapor-injection cycle}

In the previous sections, it has been established expressions to characterize the evaporator mass flow rate, the power input and the injection mass flow rate of an SCVI. In this section, these expressions are used in a simple model of a vapor-injection cycle in order to predict the compressor behavior independently of the injection mechanism used in the cycle.

Fig. 9 shows a general scheme of the vapor-injection cycle, in which the box with dashed line represents the injection mechanism.
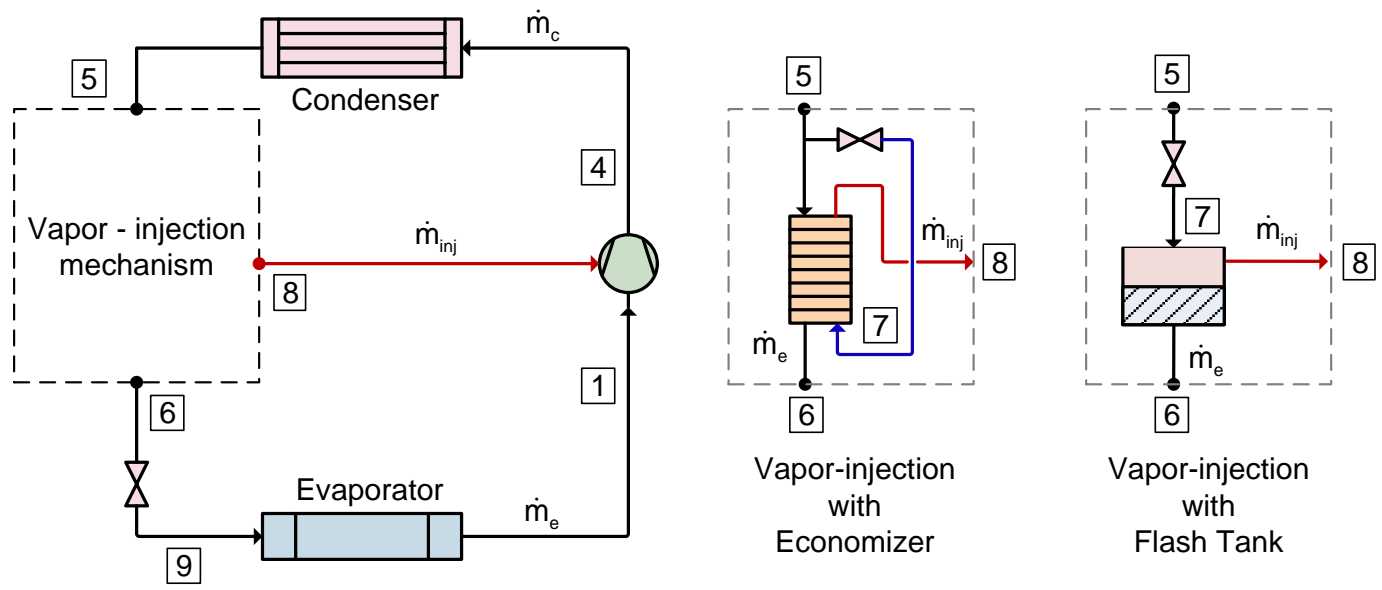

Fig. 9 - General scheme of the vapor-injection cycle.

The input data of the model are $\mathrm{T}_{\mathrm{c}}, \mathrm{T}_{\mathrm{e}}, \mathrm{SH}, \mathrm{SC}$, and $\mathrm{SH}_{\mathrm{inj}}$. The unknown variables are $\dot{\mathrm{m}}_{\mathrm{e}}, \dot{\mathrm{m}}_{\mathrm{inj}}$, $\dot{\mathrm{E}}, \mathrm{P}_{\mathrm{int}}, \mathrm{h}_{6}$, and $\mathrm{h}_{8}$.

The model equations of the vapor-injection cycle are as follows: 


$$
\begin{gathered}
\dot{\mathrm{m}}_{\mathrm{e}}=\mathrm{f}\left(\mathrm{T}_{\mathrm{e}}, \mathrm{T}_{\mathrm{c}}, \mathrm{C}_{1} \ldots \mathrm{C}_{10}\right) \\
\dot{\mathrm{m}}_{\mathrm{c}}=\dot{\mathrm{m}}_{\mathrm{e}}+\dot{\mathrm{m}}_{\mathrm{inj}} \\
\dot{\mathrm{m}}_{\mathrm{c}} \mathrm{h}_{5}=\dot{\mathrm{m}}_{\mathrm{e}} \mathrm{h}_{6}+\dot{\mathrm{m}}_{\mathrm{inj}} \mathrm{h}_{8} \\
\dot{\mathrm{Q}}_{\text {tra }}=\mathrm{f}\left(\mathrm{UA}, \mathrm{T}_{5}, \mathrm{~T}_{7}, \dot{\mathrm{m}}_{\mathrm{e}}, \dot{\mathrm{m}}_{\mathrm{inj}}\right) \\
\dot{\mathrm{m}}_{\mathrm{inj}}=\mathrm{f}\left(\mathrm{P}_{\mathrm{e}}, \mathrm{P}_{\mathrm{int}}, \dot{\mathrm{m}}_{\mathrm{e}}\right) \\
\dot{\mathrm{E}}=\mathrm{f}\left(\mathrm{T}_{\mathrm{e}}, \mathrm{T}_{\mathrm{c}}, \mathrm{T}_{\text {dew,inj }}, \mathrm{C}_{1} \ldots \mathrm{C}_{11}\right)
\end{gathered}
$$

The point 5 is defined by the condensing pressure and the subcooling. The evaporator mass flow rate is calculated with the AHRI polynomial of equation (9).

The intermediate pressure and the points 6 and 8 are defined by the energy balance (equation (11)) and the heat transfer equations of the vapor-injection mechanism ( $\left.\dot{\mathrm{Q}}_{\text {tra }}\right)$. It should be pointed out that UA in equation (12) represents the model of the injection mechanism that could be have in the cycle (economizer, flash tank, etc.). Thus, in the cycle with an economizer, the equation (12) represents the heat transfer in the heat exchanger. In the cycle with a flash tank, the points 6 and 8 correspond to the bubble and dew point at the intermediate pressure respectively.

In order to close the system of equations of the vapor-injection cycle model, the obtained correlation of equation (13) must be used. As it is commented previously, this expression allows correlating the injection mass flow rate and the intermediate pressure for any system.

Once the injection mass flow rate is determinate, the condenser mass flow rate is calculated with the equation (10). Finally, the compressor power input is calculated by the modified AHRI polynomial of equation (14).

\subsection{Validation of the characterization methodology}

In order to validate the proposed characterization methodology, the results obtained in sections 4.1 and 4.2, and the vapor-injection cycle model of section 4.3 were used to predict the compressor behavior when it works in a real system. The system is a heat pump prototype with an economizer, which is available in the laboratory. The predicted data are compared with the experimental results measured in the heat pump prototype.

Table 1 (labels "c") shows the test matrix defined for the validation of the proposed methodology.

\subsubsection{Description of the experimental heat pump prototype}

The experimental bench is an air to water heat pump installed in a climatic chamber. Fig. 10 shows the schematic of the test rig used to collect the SCVI data. The system consists of three 
circuits: the heat pump circuit, the water circuit for the condenser and the air circuit for the climatic chamber.

The SCVI used in the heat pump prototype is a different compressor of the same model and size that was used in the characterization procedure. The economizer used was that recommended by the manufacturer for this compressor size, which is a brazed plate heat exchanger of $0.276 \mathrm{~m}^{2}$ of total heat transfer area.

The water circuit is in charge of controlling the condensation pressure. The evaporating temperature and superheat are controlled by the climatic chamber temperature control and the electronic expansion valve EEV-2. The secondary electronic expansion valve (EEV-1 in Fig. 10) mainly controls the intermediate superheat by adjusting the intermediate pressure.

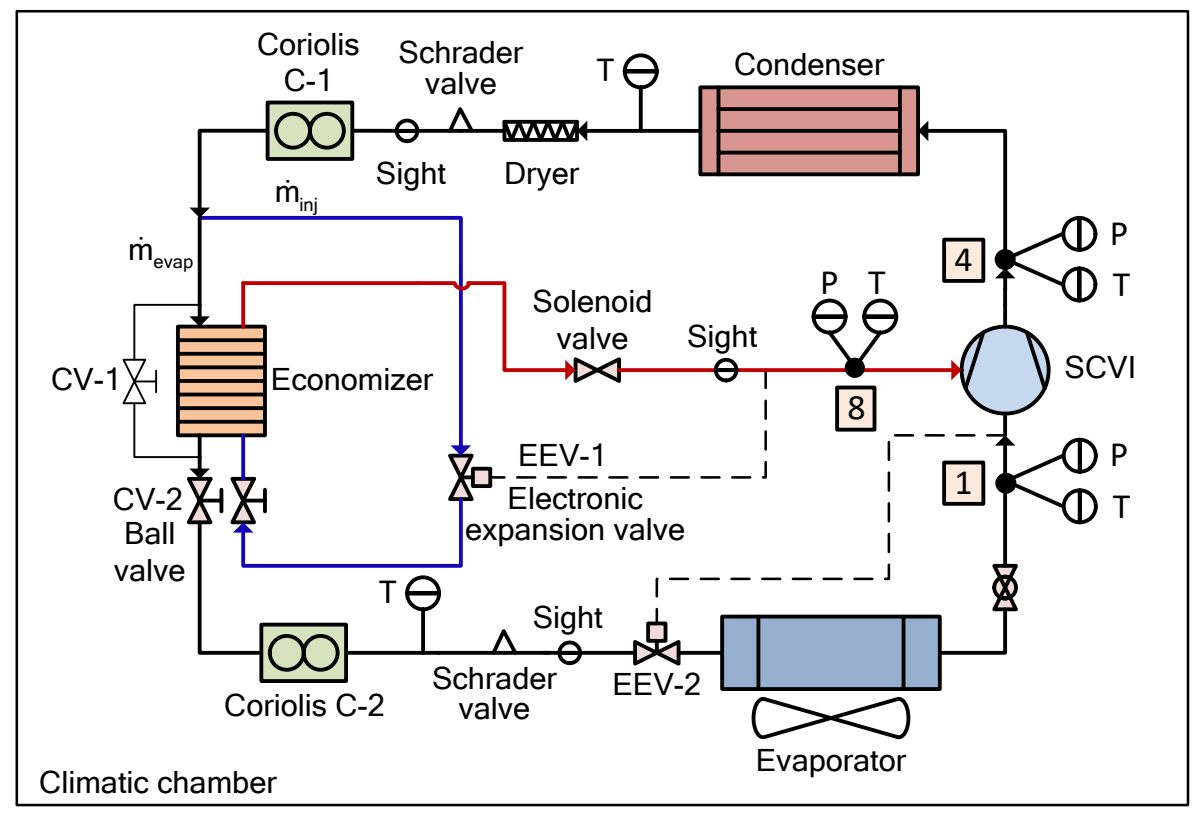

Fig. 10 - Scheme of the heat pump prototype.

The system is controlled by four PID loops, which can set the condensing pressure, evaporating pressure, compressor inlet superheat, and injection superheat acting on the water condenser flow rate, climatic chamber temperature, valve EEV-2, and valve EEV-1 respectively. The system is also able to work with the traditional single-stage cycle by closing a solenoid valve placed in the injection line.

Regarding the instrumentation, the system is equipped with two Coriolis mass flow meters with an accuracy of $0.05 \%$, an electrical power meter with an accuracy of $0.1 \%$, three pressure transducers with an accuracy of $0.2 \%$, and five resistance temperature detectors (RTD) with an accuracy of $0.1 \mathrm{~K}$. 


\subsubsection{Experimental results and validation of the predicted data}

The SCVI compressor was tested with R407C as a refrigerant. The tests were performed according to the following parameters: inlet compressor superheat of $10 \mathrm{~K}$, intermediate superheat of $5 \mathrm{~K}$ and subcooling of $0 \mathrm{~K}$.

The injection mass flow rate and the economizer capacity were calculated with equations (15) and (16) respectively.

$$
\begin{gathered}
\dot{\mathrm{m}}_{\text {inj }}=\dot{\mathrm{m}}_{\mathrm{c}}-\dot{\mathrm{m}}_{\mathrm{e}} \\
\dot{\mathrm{Q}}_{\text {eco }}=\dot{\mathrm{m}}_{\text {inj }}\left(\mathrm{h}_{8}-\mathrm{h}_{7}\right)=\dot{\mathrm{m}}_{\mathrm{e}}\left(\mathrm{h}_{5}-\mathrm{h}_{6}\right)
\end{gathered}
$$

Table 3 summarizes the experimental results of the compressor performance working in the operating conditions of Table 1 (labels “b”).

Table 3 - Experimental results of the compressor performance in the heat pump prototype.

\begin{tabular}{|c|c|c|c|c|c|c|c|c|c|c|}
\hline $\begin{array}{c}\mathbf{T}_{\mathbf{e}} \\
\left({ }^{\circ} \mathrm{C}\right)\end{array}$ & $\begin{array}{c}\mathbf{T}_{\mathbf{c}} \\
\left({ }^{\circ} \mathrm{C}\right)\end{array}$ & $\begin{array}{c}\dot{\mathbf{E}} \\
(\mathrm{kW})\end{array}$ & $\begin{array}{c}\dot{\mathbf{Q}}_{\text {eco }} \\
(\mathrm{kW})\end{array}$ & $\begin{array}{c}\dot{\mathbf{m}}_{\mathbf{e}} \\
\left(\mathrm{g} \mathrm{s}^{-1}\right)\end{array}$ & $\begin{array}{c}\dot{\mathbf{m}}_{\text {inj }} \\
\left(\mathrm{g} \mathrm{s}^{-1}\right)\end{array}$ & $\begin{array}{c}\mathbf{P}_{\text {int }} \\
(\mathrm{kPa})\end{array}$ & $\begin{array}{c}\mathbf{P}_{\mathbf{e}} \\
(\mathrm{kPa})\end{array}$ & $\begin{array}{c}\mathbf{P}_{\mathbf{c}} \\
(\mathrm{kPa})\end{array}$ & $\boldsymbol{\eta}_{\mathbf{c}}$ & $\boldsymbol{\eta}_{\mathbf{v}}$ \\
\hline-8.2 & 40.03 & 4.04 & 1.78 & 62.10 & 9.65 & 578 & 342.30 & 1542.53 & 0.65 & 0.93 \\
\hline-16.53 & 49.6 & 4.74 & 2.2 & 42.91 & 13.19 & 517 & 247.53 & 1968.20 & 0.583 & 0.88 \\
\hline-8.3 & 49.67 & 4.96 & 2.29 & 60.86 & 13.55 & 630 & 341.02 & 1971.61 & 0.634 & 0.921 \\
\hline-3.15 & 50.69 & 5.12 & 2.26 & 73.01 & 12.96 & 709 & 412.02 & 2021.88 & 0.651 & 0.919 \\
\hline 2.03 & 49.99 & 5.12 & 2.09 & 88.19 & 11.55 & 802 & 494.35 & 1987.28 & 0.666 & 0.928 \\
\hline-19.39 & 60.31 & 5.697 & 2.13 & 36.43 & 14.46 & 524 & 220.20 & 2547.16 & 0.51 & 0.84 \\
\hline-8.27 & 59.24 & 5.96 & 2.7 & 58.95 & 17.37 & 700 & 341.40 & 2483.91 & 0.593 & 0.876 \\
\hline 9.73 & 59.93 & 6.49 & 2.68 & 112.76 & 016.12 & 1045 & 639.27 & 2524.55 & 0.66 & 0.919 \\
\hline
\end{tabular}

As it was commented previously, the results shown in Table 3 are compared with the predicted data for the model described in section 4.3. In the model, the equations (9), (13) and (14) were obtained from the compressor characterization results of sections 4.1 and 4.2. The equation (12) considers the heat exchanger geometry used in the heat pump prototype as an economizer.

Fig. 11 shows the comparison of the predicted and experimental results of the evaporator mass flow rate (a), injection mass flow rate (b), intermediate pressure (c), and compressor power input (d).

All predicted variables shown a correct agreement with the experimental results, the maximum deviation does not exceed the $5 \%$ in all cases.

Table 4 shows the maximum and average deviation of the predicted results. In addition, in order to establish if the obtained deviations for the SCVI are acceptable, we have compared these deviations with the deviations obtained in a single-stage scroll compressor. For that, a singlestage scroll compressor $\left(17.1 \mathrm{~m}^{3} \mathrm{~h}^{-1}\right)$ was tested, and the measurements of evaporator mass flow rate and compressor power inputs were compared with the obtained values with AHRI polynomials from manufacturer data (equation (1)). It has to note that AHRI polynomials are 
widely accepted to estimate the performance of single-stage compressors. The maximum and average deviations are also presented in Table 4.

a)

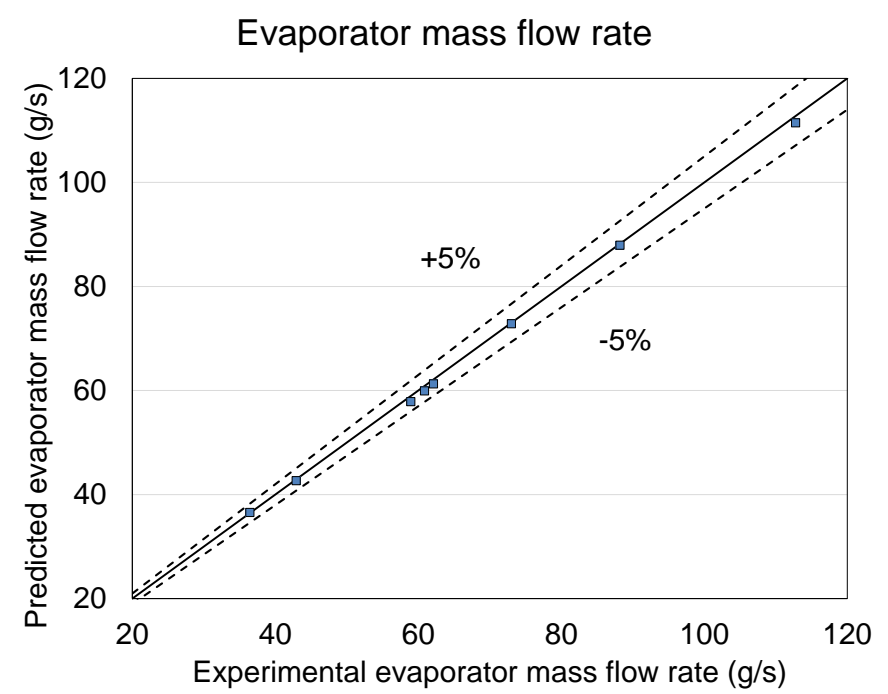

c)

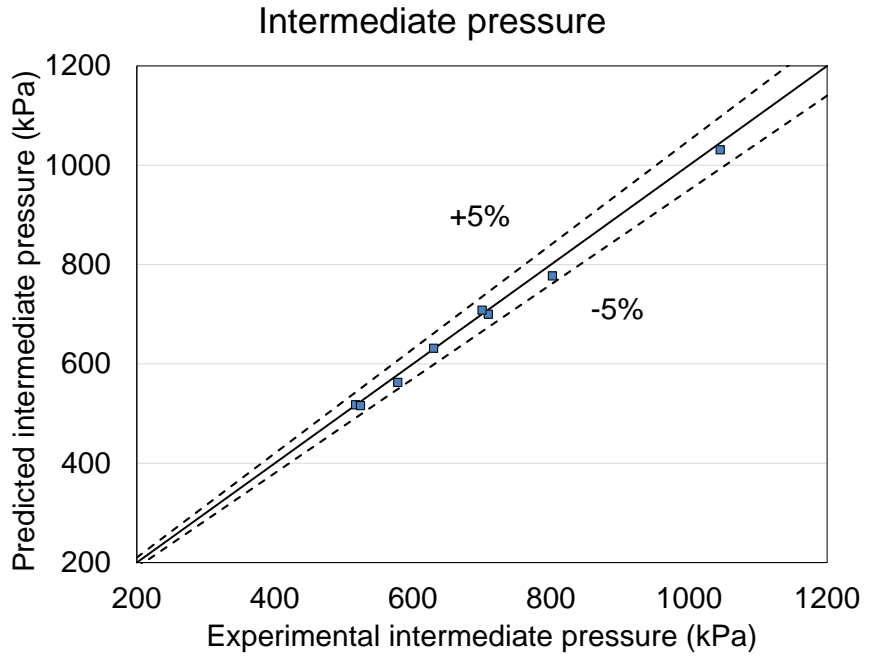

b)

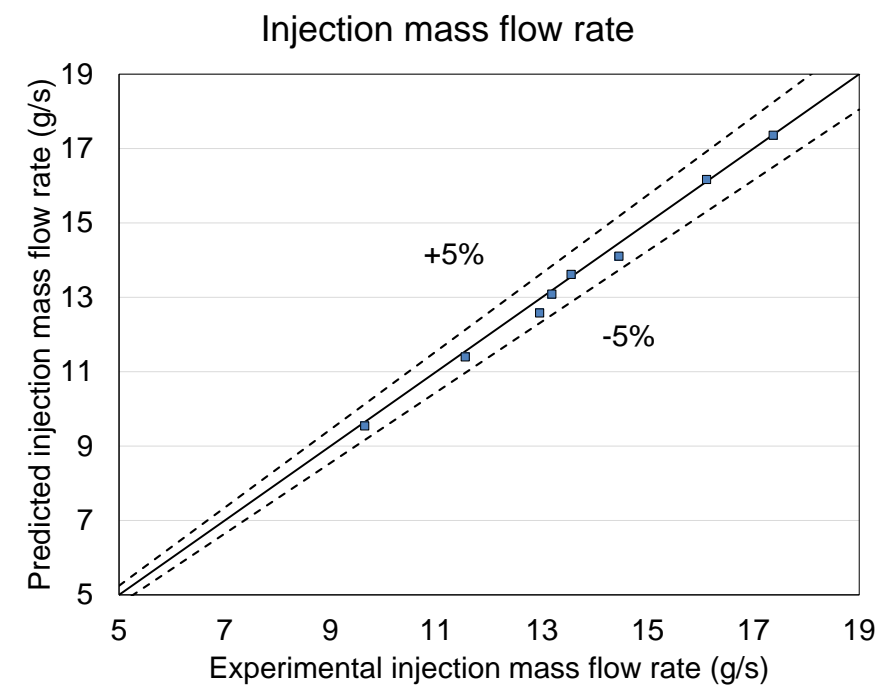

d)

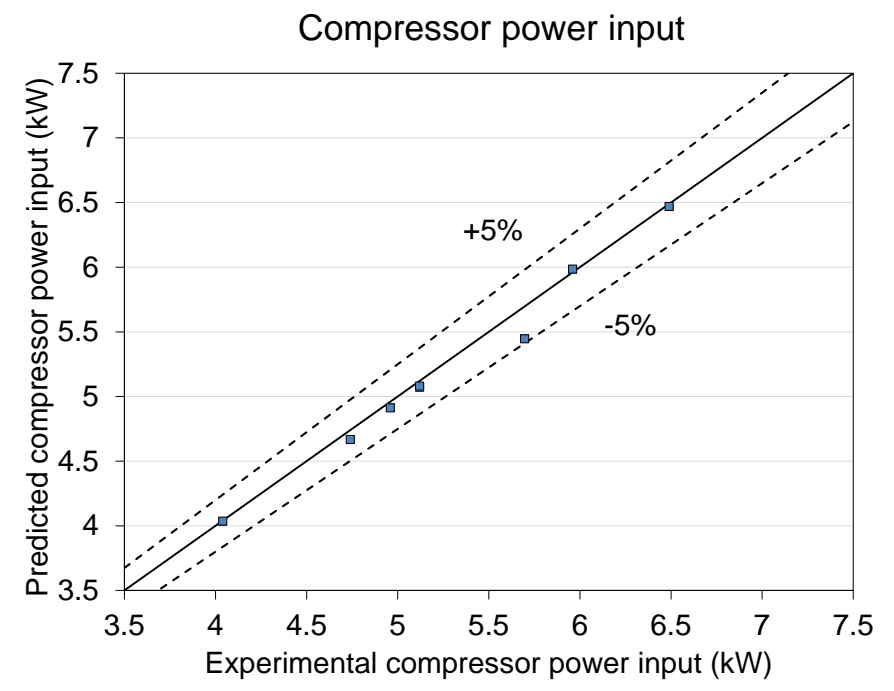

Fig. 11 - Comparison of the experimental and predicted data of the SCVI.

Table 4 - Deviations of the simulation results.

\begin{tabular}{|c|cccc|cc|}
\hline Relative deviations & \multicolumn{3}{|c|}{ Vapor-injection compressor } & \multicolumn{2}{c|}{ Single-stage compressor } \\
\cline { 2 - 7 } (Calc.-Test)/Test x 100 & $\dot{\mathbf{E}}$ & $\dot{\mathbf{m}}_{\mathbf{e}}$ & $\dot{\mathbf{m}}_{\text {inj }}$ & $\mathbf{P}_{\text {int }}$ & $\dot{\mathbf{m}}_{\mathbf{e}}$ & $\dot{\mathbf{E}}$ \\
\hline Maximum (\%) & -4.40 & -1.80 & -2.91 & -3.13 & 5.68 & -5.07 \\
Average (\%) & -1.08 & -0.79 & -0.95 & -1.06 & 2.63 & -1.26 \\
\hline
\end{tabular}

The deviations obtained in the SCVI are even lower than the obtained in the single-stage compressor. Thus, the accuracy of the predicted results is satisfactory for the characterization of this kind of compressor technology. 
It is important to note that the compressor characterization was performed in a calorimetric test bench, while the results of the experimental validation are obtained in a very different installation (heat pump prototype with economizer). This fact gives us an idea of the generality of the proposed methodology, and how useful it is for compressor manufacturers when providing information about their compressors and for the designers to estimate more reliably the compressor behavior in a particular application.

\section{CONCLUSIONS}

In this paper, a characterization methodology for vapor-injection scroll compressors is proposed and following conclusions can be drawn from the study:

- For the compressor characterization, a modified calorimeter test bench able to control independently the intermediate pressure and injection superheat has been used. A vaporinjection scroll compressor was tested over a range of evaporating and condensing conditions. For each operating condition, the intermediate pressure and the injection superheat were fixed.

- From the characterization results, the injection mass flow rate was correlated with the injection pressure. The resultant expression was a linear equation with a correlation factor higher than 0.99. This correlation is an intrinsic characteristic of each compressor and it is independent of the way in which the injection is performed. The intermediate condition correlation is an additional AHRI polynomial required to characterize vapor-injection scroll compressors. In addition, two polynomials were defined to characterize the evaporator mass flow rate and the compressor power input.

- Regarding the analysis of the influence intermediate pressure, the compressor power input varies linearly with the intermediate pressure, for this reason, the defined AHRI polynomial for the compressor power input contains an additional term in order to consider the effect of the intermediate pressure. On the other hand, the influence of the intermediate pressure on the evaporator mass flow rate is negligible.

- A simple model of vapor-injection cycle was proposed in order to estimate the compressor behavior of an SCVI working in a real installation with a particular injection mechanism.

- The characterization methodology was validated using a different compressor of the same model than the compressor used in the characterization installed in a heat pump prototype with an economizer. The experimental results were compared with predicted data obtained from a model of a vapor-injection cycle. Results shown a correct agreement between predicted and measured data, the maximum deviation does not exceed the $5 \%$ for evaporator mass flow rate, injection mass flow rate, and compressor power input.

- The proposed methodology permits to evaluate the compressor performance independently of the injection mechanism and the system design. This characterization methodology can be a 
useful tool for compressor manufacturers when providing information about their compressors and to the designers to estimate more reliably the compressor behavior in a particular application.

\section{Acknowledgments}

Fernando M. Tello-Oquendo acknowledges the financial support provided by the “CONVOCATORIA ABIERTA 2013-SEGUNDA FASE" program, which was funded by the SENESCYT (“Secretaría Nacional de Educación Superior, Ciencia, Tecnología e Innovación”) (Grand No 2015-AR37665) of Ecuador.

\section{REFERENCES}

AHRI Standard 540, 2015. Standard for performance rating of positive displacement refrigerant compressors and compressors units. 2111 Wilson Boulevard, Suite 500 Arlington, VA 22201, USA.

Bertsch, S., Groll, E., 2008. Two-stage air-source heat pump for residential heating and cooling applications in northern U.S. climates. Int. J. Refrigeration. 31, 1282-1292.

Cho, H., Chung, J. T., Kim, Y., 2003. Influence of liquid refrigerant injection on the performance of an inverter-driven scroll compressor. Int. J. Refrigeration. 31, 87-94.

Ding, Y., Chai, Q., Ma, G., Jiang, Y., 2004. Experimental study of an improved air source heat pump. Energ. Convers. Manage. 45, 2393-2403.

Dutta, A. K., Yanagisawa, T., Fukuta, M., 2001. An investigation of the performance of a scroll compressor under liquid refrigerant injection. Int. J. Refrigeration. 24, 577-587.

Emerson Climate Technologies, 2015. Economized Vapor Injection (EVI) Compressors, Bulletin AE4-1327 R12. Emerson Climate Technologies, Inc..

Feng, C., Kai, W., Shouguo, W., Ziwen, X., Pengcheng, S., 2009. Investigation of the heat pump water heater using economizer vapor injection system and mixture of R22/R600a. Int. J. Refrigeration. 32, 509-514.

Lemmon, E., Huber, M., McLinden, M., 2010. NIST Standard Reference Database 23:Reference Fluid Thermodynamic and Transport Properties-refprop. Version 9.0. National Institute of Standards and Technology, Standard Reference Data Program, Gaithersburg.

Ma, G., Chai, Q., 2004. Characteristics of an improved heat-pump cycle for cold regions. Appl. Energ. 77, 235-247.

Ma, G., Chai, Q., Jiang, Y., 2003. Experimental investigation of air-source heat pump for cold regions. Int. J. Refrigeration. 26, 12-18.

Ma, G., Zhao, H., 2008. Experimental study of a heat pump system with flash-tank coupled with scroll compressor. Energ. Buildings. 40, 697-701. 
Moesch, T. W., Bahman, A. M., Groll, E. A., 2016. Performance Testing of a Vapor Injection Scroll Compressor with R407C. In: Proceedings of $23^{\text {rd }}$ International Compressor Engineering Conference at Purdue. West Lafayette, IN, USA. Paper 1327.

Navarro, E., Redón, A., Gonzálvez, J., Martinez, I., 2013. Characterization of a vapor injection scroll compressor as a function of low, intermediate and high pressures and temperature conditions. Int. J. Refrigeration. 36, 1821-1829.

Qiao, H., Aute, V., Radermacher, R., 2015a. Transient modeling of a flash tank vapor injection heat pump system - Part I: Model development. Int. J. Refrigeration. 49, 169-182.

Qiao, H., Xu, X., Aute, V., Radermacher, R., 2015b. Transient modeling of a flash tank vapor injection heat pump system - Part II: Simulation results and experimental validation. Int. J. Refrigeration. 49, 183-194.

Roh, C. W., Kim, M. S., 2011. Effects of intermediate pressure on the heating performance of a heat pump system using R410A vapor injection technique. Int. J. Refrigeration. 34, 19111921.

Roh, C. W., Kim, M. S., 2012. Comparison of the heating performance of an inverter_driven heat pump system using R410A vapor_injection into acccumulator and compressor. Int. J. Refrigeration. 35, 434-444.

UNE-EN 13771-1, 2003. Compressors and condensing units for refrigeration - Performance testing and test methods.

Wang, B., Li, X., Shi, W., Yan, Q., 2007. Design of experimental bench and internal pressure measurement of scroll compressor with refrigerant injection. Int. J. Refrigeration. 30, 179186.

Wang, B., Shi, W., Han, L., Li, X., 2009a. Optimization of refrigeration system with gas-inyected scroll compressor. Int. J. Refrigeration. 32, 1544-1554.

Wang, B., Shi, W., Li, X., 2009c. Numerical analysis on the effects of refrigerant injection on the scroll compressor. Appl. Therm. Eng. 29, 37-46.

Wang, B., Shi, W., Li, X., Yan, Q., 2008. Numerical research on the scroll compressor with refrigeration injection. Appl. Therm. Eng. 28, 440-449.

Wang, X., Hwuang, Y., Radermacher, R., 2009b. Two-stage heat pump system with vaporinjected scroll compressor using R410A as a refrigerant. Int. J. Refrigeration. 32, 1442-1451.

Winandy, E. L., Lebrun, J., 2002. Scroll compressors using gas and liquid injection:experimental analysis and modelling. Int. J. Refrigeration. 25, 1143-1156.

Xu, S., Ma, G., 2011. Research on air-source heat pump coupled with economized vapor injection scroll compressor and ejector. Int. J. Refrigeration. 34, 1587-1595.

Xu, S., Ma, G., Liu, Q., Liu, Z., 2013. Experiment study of an enhanced vapor injection refrigeration/heat pump system using R32. Int. J. Therm. Sci. 34, 1922-1933. 
Xu, X., Hwang, Y., Radermacher, R., 2011. Refrigerant injection for heat pumping/air conditioning systems: literature review and challenges discussions. Int. J. Refrigeration. 34, 402-415. 